\title{
Diet quality is positively associated with indexes of muscle mass
}

\author{
E. Kelaiditi ${ }^{1}$, A. Cassidy ${ }^{1}$, A. Macgregor ${ }^{2}$, T. Spector ${ }^{2}$ and A. Welch ${ }^{1}$ \\ ${ }^{1}$ Department of Nutrition, Norwich Medical School, University of East Anglia, Norwich, Norfolk, NR4 7TJ, UK \\ and ${ }^{2}$ Department of Twin Research and Genetic Epidemiology, King's College London, SE1 7EH, UK
}

The causes of age-related loss of muscle mass and sarcopenia (loss of muscle mass and strength) are incompletely understood ${ }^{(1)}$ but evidence suggests that diet may play a role in the conservation of muscle mass, potentially through effects on chronic inflammation which has been found to mediate muscle loss ${ }^{(2)}$. The aim of the current study was to assess associations between diet quality, according to three predefined diet quality scores (The diet quality index (DQI) and healthy diet indicator (HDI) and Mediterranean diet score (MDS)), and indexes of muscle mass ${ }^{(3,4,5,6)}$. All three scores have been associated with reduced mortality and focus on fruits and vegetable consumption and SFA. The DQI and HDI also include percentage total fat, PUFA, whole grains, carbohydrates, protein, Na and Ca whereas the MDS includes legumes, cereals, fish, dairy products, meat, and the ratio of mono- and poly to saturated fat ${ }^{(3,4,5,6)}$.

A cross sectional study among 2690 female twin pairs from the twins UK adult twin registry, aged 18-79 years was conducted ${ }^{(7)}$. Ethical approval was obtained from the St. Thomas's Hospital Research Ethics committee and informed consent obtained from all subjects. Body composition was measured using dual-energy X-ray absorptiometry. Indexes of muscle mass, \% fat-free mass (FFM\%) and fat free mass index (FFMI - lean mass in $\mathrm{kg} / \mathrm{height}^{2}$ ), were compared between quartiles or quintiles of the diet scores after adjustment for age, physical activity, smoking, and for the FFMI for total body fat. Analysis was performed in SPSS version 16.0 (SPSS Inc, Chicago, IL).

Mean age was 48.2 years, mean FFM\% was $61 \%$, and mean FFMI was $15 \mathrm{~kg} / \mathrm{m}^{2}$. Indexes of muscle mass (FFM\%) showed a trend with all three diet scores between the top and bottom quartile or quintile, with differences of FFM\% of $0.7 \%$ for the MDS (P for trend $=0.012$ ), of $1.1 \%$ for the HDI $(\mathrm{P}$ for trend $=0.001$ ) and $0.2 \%$ for the DQI ( $\mathrm{P}$ for trend $=0.417$ ). For FFMI the corresponding differences were $0.2 \mathrm{~kg} / \mathrm{m}^{2}$ for the MDS ( $\mathrm{P}$ for trend $\left.=0.004\right), 0.3 \mathrm{~kg} / \mathrm{m}^{2}$ for the HDI $(\mathrm{P}$ for trend $=0.008)$ and $0.4 \mathrm{~kg} / \mathrm{m}^{2}$ for the DQI (P for trend $<0.001$ ).

\begin{tabular}{|c|c|c|c|c|c|c|c|c|c|c|c|c|c|c|c|}
\hline & \multicolumn{5}{|c|}{ MDS } & \multicolumn{5}{|c|}{ HDI } & \multicolumn{5}{|c|}{ DQI } \\
\hline & \multicolumn{2}{|c|}{ Q1 $n 814$} & \multicolumn{2}{|c|}{ Q4 $n 808$} & \multirow[b]{2}{*}{$P$ for trend } & \multicolumn{2}{|c|}{ Q1 $n 808$} & \multicolumn{2}{|c|}{ Q4n 448} & \multirow[b]{2}{*}{$\mathrm{P}$ for trend } & \multicolumn{2}{|c|}{$\mathrm{Q} 1 n 699$} & \multicolumn{2}{|c|}{ Q5 $n 715$} & \multirow[b]{2}{*}{$\mathrm{P}$ for trend } \\
\hline & Mean & SE & Mean & $\mathrm{SE}$ & & Mean & SE & Mean & SE & & Mean & $\mathrm{SE}$ & Mean & SE & \\
\hline$\overline{\mathrm{FFM}}^{I}$ & 60.8 & 0.21 & 61.5 & 0.21 & 0.012 & 60.9 & 0.21 & 62.0 & 0.28 & 0.001 & 60.8 & 0.23 & 61.0 & 0.22 & 0.417 \\
\hline FFMI $^{2}$ & 14.8 & 0.05 & 15.0 & 0.05 & 0.004 & 14.9 & 0.05 & 15.2 & 0.07 & 0.008 & 14.7 & 0.06 & 15.1 & 0.06 & $<0.001$ \\
\hline
\end{tabular}

FFM\%, Fat-free mass (\%); FFMI, Fat-free mass index $\left(\mathrm{kg} / \mathrm{m}^{2}\right)$ values are means and SE in quintiles 1 and $4 / 5$ of the derived diet scores.

${ }^{1}$ Adjusted for age, physical activity, smoking history.

${ }^{2}$ Also for total body fat $(\mathrm{kg})$.

In conclusion, we observed significant positive associations between better diet quality and indexes of muscle mass in women. The greatest association was between the DQI and the FFMI and was equivalent to $\approx 3 \%$ of the population mean for FFMI, after having accounted for the effects of age, total body fat, physical activity and smoking. The findings from this study suggest that, in women, the quality of the diet may be important in maintaining fat free mass.

1. Cruz-Jentoft AJ, Baeyens JP, Bauer JM et al. (2010) Age Ageing 39, 412-423.

2. Ferrucci L, Harris TB, Guralnik JM et al. (1999) J Am Geriatr Soc 47, 639-646.

3. Seymour JD, Calle EE, Flagg EW et al. (2003) Am J Epidemiol 157, 980-988.

4. Huijbregts P, Feskens E, Rasanen L et al. (1997) BMJ 315, 13-17.

5. Fung TT, Rexrode KM, Mantzoros CS et al. (2009) Circulation 119, 1093-1100.

6. Trichopoulou A, Orfanos P, Norat T et al. (2005) BMJ 330, 991.

7. Cassidy A, Skidmore P, Rimm EB et al. (2008) J Nutr 139, 353-358. 